\title{
AUTOMATED COCONUT CHOPPING MACHINE
}

\author{
AhilaRajan Jayasankar ${ }^{1 *}$, Fedor Gubarev ${ }^{1}$, Sadasivan Theekay Veetil ${ }^{2}$, Samyak Samar ${ }^{2}$, \\ Ankit Kumar $^{2}$ \\ ${ }^{1}$ National Research Tomsk Polytechnic University, 634050, Tomsk, Russia \\ ${ }^{2}$ Manipal University Jaipur, VPO Dehmikalan, Jaipur, Rajasthan 303007, India
}

\begin{abstract}
The paper explains the purpose, working principle, advantages and applications of the new machine named "Automated Coconut Chopper". The main purpose to design this machine is to automate an activity of a farmer/labor i.e. chopping of green coconut in order to consume water inside it and also designed considering the two main factors safety and cost.
\end{abstract}

\section{Introduction}

In India, there are huge numbers of coconut tree cultivation and wide range of its consumption, one of the major consumption is drinking the fluid inside the coconut. Usually a labor is trained to cut the coconut. As the labor/farmers are disappearing gradually, this machine helps to overcome or to substitute this action.

In India, coconut is cultivated mainly in the coastal tracts of Kerala, Tamil Nadu, Karnataka, Andhra Pradesh, Orissa, West Bengal, Pondicherry, and Maharashtra and in the islands of Lakshadweep, Andaman and Nicobar. By the late 1970s it accounted for some $68 \%$ of total production in India and at one stage some 899, 198 hectares were reportedly under cultivation. Today Kerala produces roughly $45 \%$ of India's coconuts, with some $92 \%$ of total production lying in the southern Indian states and Kerala's neighbors [1].

On the increased necessity of time and lack of skilled labor the field of automation and automatic devices is developing in a wide range. To automate a day to day routine activity or to easier an activity, we designed an automated machine "Automated coconut chopper" the combination of various basic mechanical mechanism and only with the scrub materials. The main purpose of this machine is to make "Green coconut" directly available for consuming with reduced intermediate labors.

On the list of various catering machines like SIRMAN vegetable cutter, peeling machine, grinders, roaster, cashew peeling machines from various manufactures we designed a new machine which make the chopping of green coconut easier and also make it economically feasible by all kind of man [2].

\footnotetext{
*Corresponding author: ahilarajanj@gmail.com
} 


\section{Description of Mechanical system}

The general principles of machine design are given in books [3-10]. According to the purposes of projected device, we have suggested and made the following mechanical parts. The overall schematic diagram is presented in Figure 1.

BASE PLATFORM is the base of entire system made of wood with the size of $(5 \times 4)$ inches. All the components like conveyor, cutting stand mechanism, drilling mechanism, all other motors and electrical components are all mounted on it. All the performance or actions of the machine are held under this area or within the base platform.

COCONUT HOLDER is a device where the green coconut is placed and holds for the entire process under taken by the machine. And it is suited on the conveyor system. The overall mechanical view of the coconut holder is shown in the Figure 2, $a$. The base structure is a rigid component of the entire mechanism, wood as a base material is considered due to the load factor. And only this portion of the coconut holder is fastened to the conveyor belt. Holding jaw is the only component is in direct contact with the green coconut. There are two holding jaws in which one is rigid and other is movable. Material considered for this element is wood strongly coated with rubber. Coated rubber helps in strong grip. Rotating rod is fixed at the mid attaching to the base structure and movable jaw. Rod is made of steel and externally threaded for certain region. The movable jaw is assembled to this in order to perform translate action. The working principle or the mechanism is plain screw vice mechanism. Basically all components are rigid except movable jaw and connecting rod. The movable jaw moves to and fro on rotating the connecting rod.

CONVEYOR is used to transfer the coconut to different task and return back to its original position automatically. Flat belt conveyor is used. Power transmission from the motor is done by chain drives. It is considered upon the factor heavy load obtained by the objects and operations performed in the machine. Two chain drives are placed on both sides of the conveyor and driven by a DC motor which is controlled by the controller. Belt conveyor is a machine transporting material in a continuous way by friction drive. It is mainly composed by rack, conveyor belt, belt roll, tensioning device and gearing. Belt conveyor is composed by two endpoint pulleys and a closed conveyor belt. The pulley that drives conveyor belt rotating is called drive pulley or transmission drum; the other oneonly used to change conveyor belt movement direction-is called bend pulley. Drive pulley is driven by the motor through reducer, and conveyor belt dragging relies on the friction drag between the drive pulley and the conveyor belt. The drive pulleys are generally installed at the discharge end in order to increase traction and be easy to drag. Material is fed on the feed-side and landed on the rotating conveyor belt, then rely on the conveyor belt friction to be delivered to discharge end. 


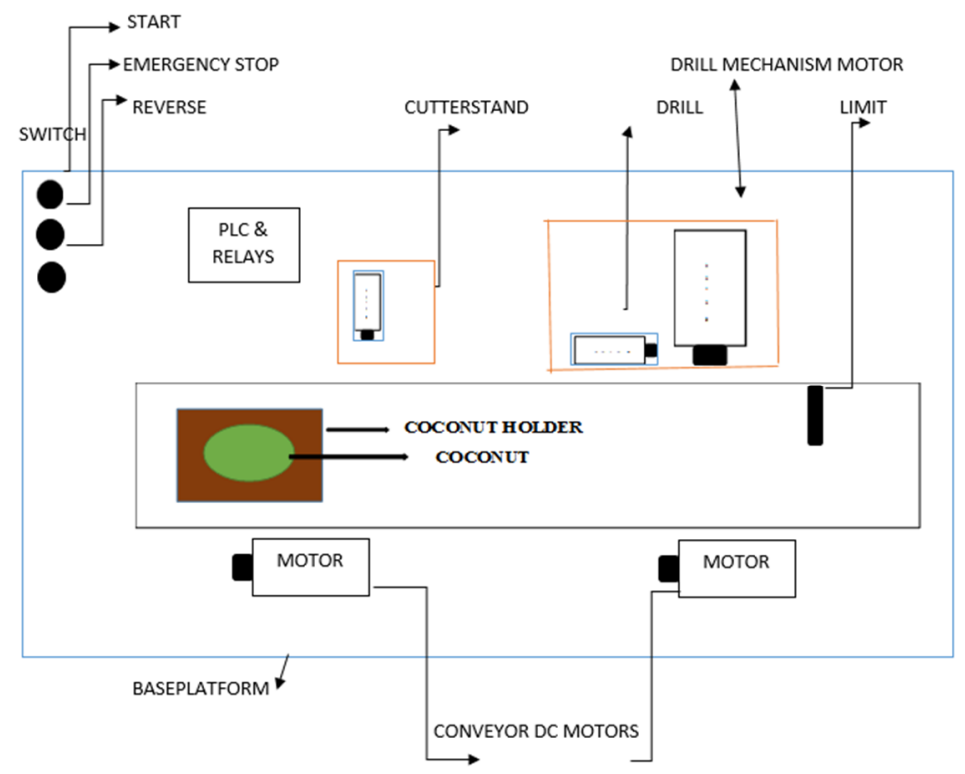

Figure 1. Overall schematic diagram.

CUTTING MECHANISM is used in system for chopping the certain top layer of the coconut. This element consists of rigid stand made of steel fastened to the base platform rigidly holding the cutting motor with the support of holding plate rigidly. The holding plate is adjustable to any height (depends upon the size of coconut).

CHAINDRIVES are common bicycle drives as the project was done by scrub.

DRILLING MECHANISM is used to give automatic feed to the drilling motor. The drill mechanism is shown in Figure 2, $b$. It consists of base structure made of steel fixed to the base platform rigidly to support the entire operation. Holding plate holds the drill motor and it is assembled to the rotating rod in order to perform up and down movement. The connecting rod is also steel and externally threaded to the certain portion where the holding plate is assembled. The rotary motion of this element is done by chain drives which are connected to the DC motor controlled by the conveyor. The working principle of this mechanism is the connecting rod is rotated by motor connected with the chain drive and due to this rotation the holding plates tends to move up and down. This leads as the automatic feed of the drill motor.

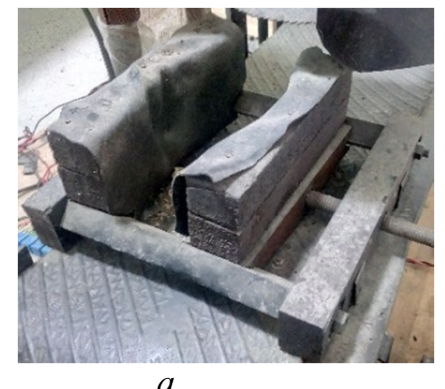

$a$
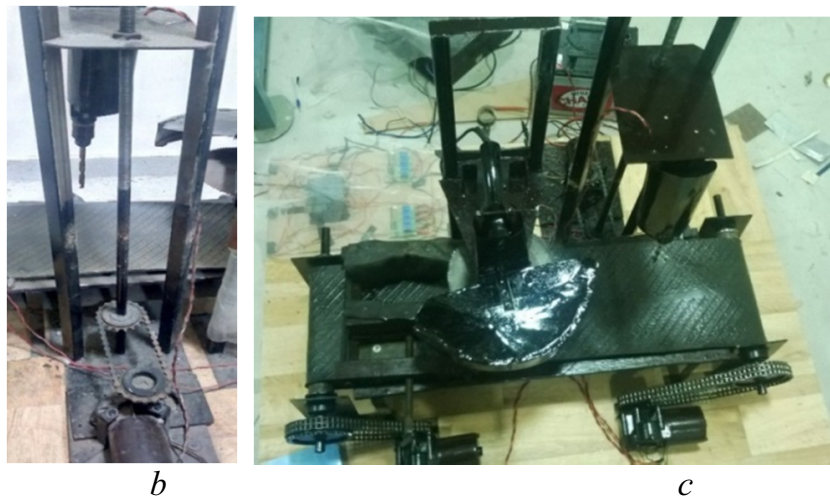

Figure 2. Parts of the coconut chopping machine: a) coconut holder; b) drill mechanism; c) final assembled machine. 


\section{Description of Electrical system}

The BRAIN of the automation system in this machine is the PLC controller (Siemens S7-200 [11]) which controls all kinds of inputs and output accordingly. Depending on the load of the conveyor system two DC motors are used as the project is done from the scrub materials old wiper motors are used as CONVEYOR MOTORS and also the same kind of motor is used as DRILL MECHANISM MOTOR in which the chain sprocket is assembled on their shafts.

DRILL MOTOR is a small sized portable drilling machine (AC motor) which is modified accordingly to assemble on the hanging plate of drilling mechanism. CUTTER MOTOR is also the same motor of drill motor but replaced with the rotary cutting blades in place of drilling spindle. SWITCHES, push buttons are used for start, stop, and reverse switches which gives signal to the controller and also limit switch is also placed on the conveyor system in order to perform certain actions according to controller. Relays are also used to change the power supply to the actuators according to their requirements. Normally single coil relay is used for all actions except the motor reversing operation and this operation is done by double contactor relay which is more practically feasible to use.

The electrical connections are shown in Figure 3. The PLC controller is switched ON by $12 \mathrm{~V}$ DC supply on considering the types of inputs/outputs and the safety precautions. All inputs (switches) are connected to the controller according to specifications. Before all connection to the output relays are used according to the requirement. The main purpose on using single contact relay on cutter and drill motor is to switch the Power supply as the output from the controller is in DC and the motors are AC, Relay is required to switch the supply to the motor. Reversing of conveyor motor and drill mechanism motor is required as the machine needs the conveyor move to and fro and also the drill motor up and down.

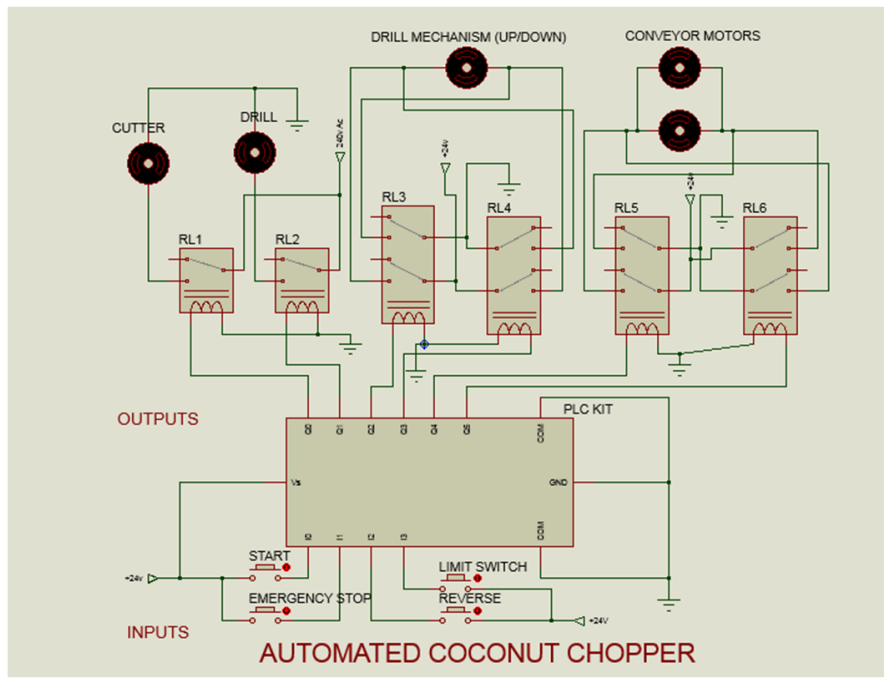

Figure 3. Electrical connections.

This circuit uses a DPDT (Double Pole Double Throw) relay to switch which direction the motor is turning. The motor is connected to both normally closed and normally open (in reverse) sides of the relay. This in effect reverses the wiring whenever the relay is turned on or off. The minimum voltage to drive this circuit is determined by the "pickup" voltage of the relay. This is listed as $9.6 \mathrm{~V}$ - but we have found it to function properly on direct connection with the controller. 


\section{Software and operation}

The algorithm of the entire machine is shown in the Figure 4. The algorithm and program is designed according to the operations performed by the machine. The sequence of the operation performed by the machine is explained below in details.

1. Coconut is fixed/assembled to the holder (manually).

2. Start button is pressed /Machine is started.

3. The cutter motor starts simultaneously the conveyor motor rotates in forward resulting in forward movement of the conveyor.

4. Conveyor stops exact in front of drilling motor for drilling operation. This action is performed as the limit switch switches ON upon the arrival of coconut holder.

5. Drill motor starts and the drill mechanism motor rotates forward resulting as the automatic feed to the coconut. This operation is held for 10 seconds.

6. Now, drill mechanism motor is reversed in order to bring back the drilling motor to its original position. This operation is timed to 13 seconds.

7. Conveyor motor rotates in reverse resulting in rotating conveyor in reverse direction as the coconut holder is back to its original position and above action is timed to 16 seconds.

8. If the Emergency Stop button is ON all the actions are stopped suddenly and this design is considered on safety precautions.

9. If the Reverse button is ON, the conveyor rotates in reverse resulting in reverse movement of conveyor (used only after emergency stop).

According to the design and manufacturer of the PLC controller, the programming software is used in which the commanding of PLC and various main performances are done. The ladder diagram of the PLC program is shown in Figure 5. Ladder diagrams are specialized schematics commonly used to document industrial control logic systems. Hence used in this machine also.
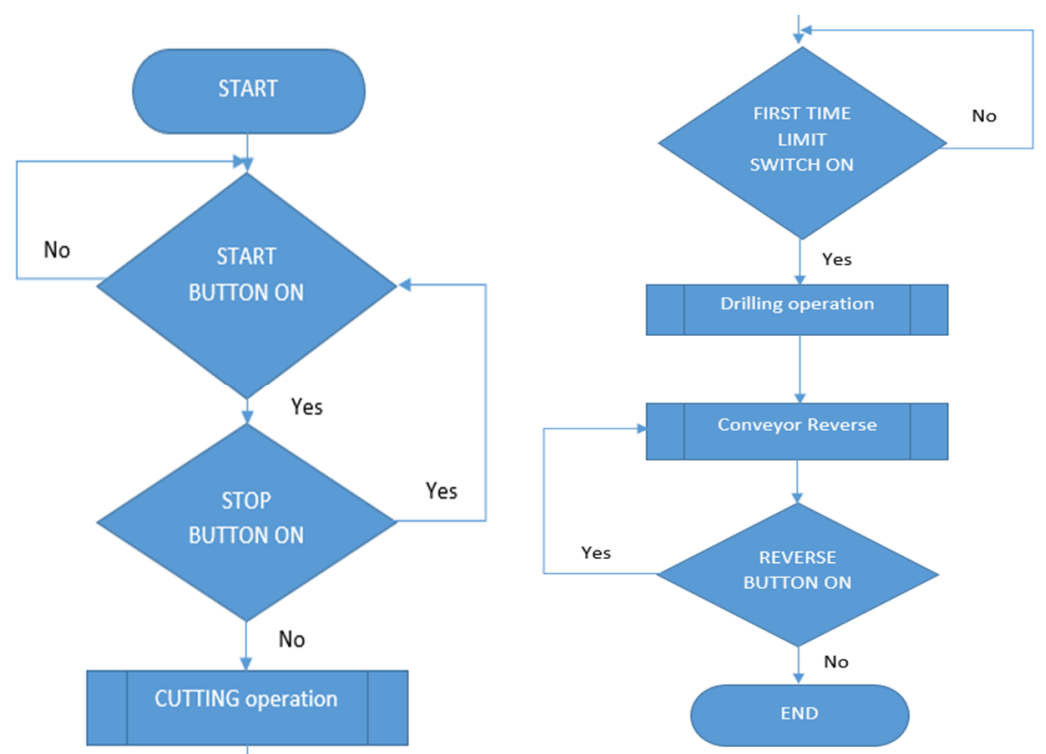

Figure 4. Algorithm of the machine operation. 


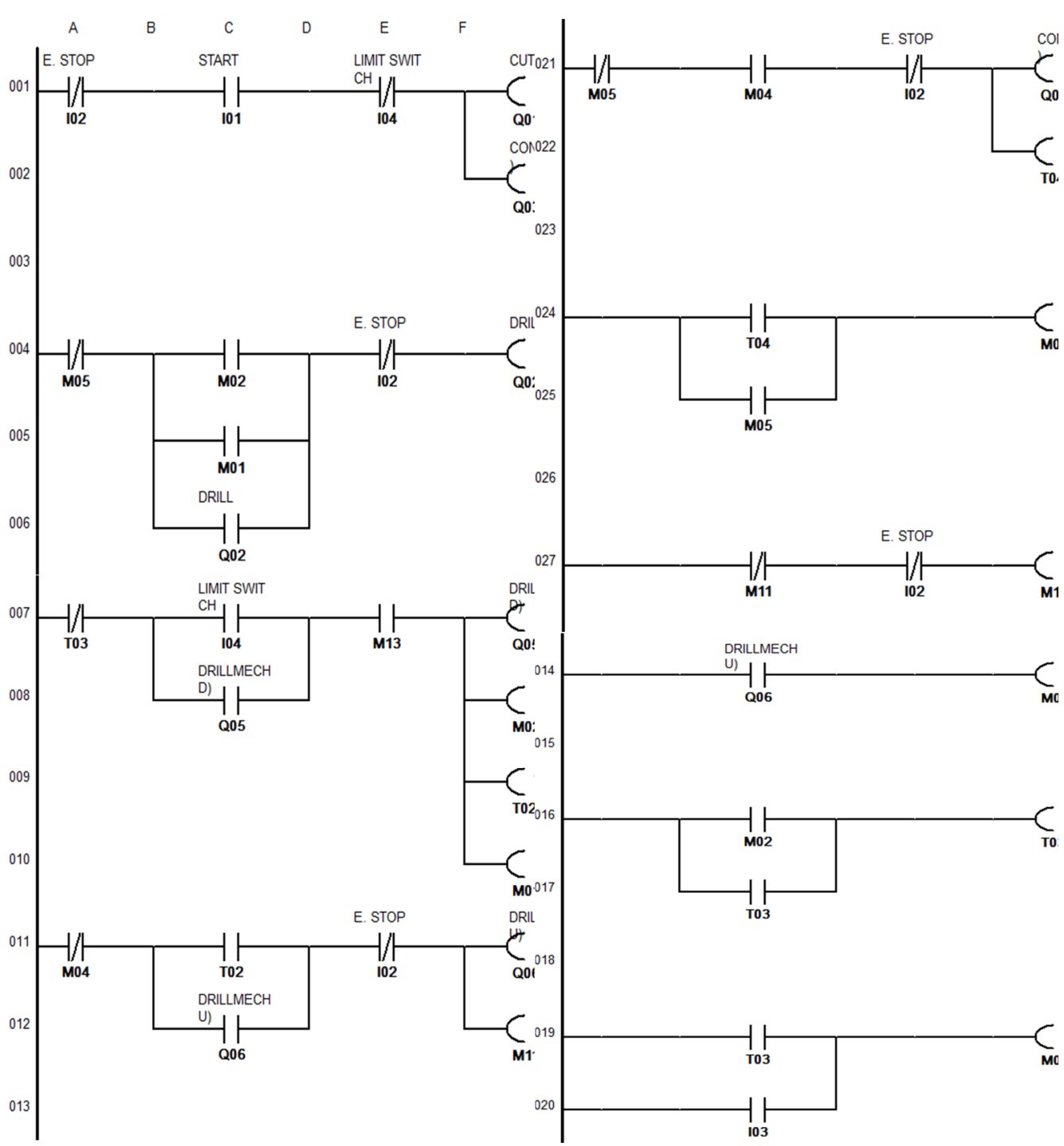

Figure 5. PLC program.

\section{Conclusion}

The final assembled view of the machine is shown in the Figure 2, $c$. The total time required to perform entire operation by this machine is around 60 seconds which is equal to the time required for labor to perform this action. The time can be reduced if all components are specially designed for this machine. As this machine is done only from the scrub materials/components the machining time is high.

The challenging part while experimenting was the rotation of conveyor due to heavy loads and balance of the belt also and this problem was cleared by having a supportive plate under the belts. The other problem was feeding the drill motor automatically, lots of wobbling was occurred and this problem was over came by adding additional supports to the drill mechanism. And the other problem was conveyor stops while the cutting operation takes place and this leads to damage of coconut also. This problem leads use to design 
additional motors to the conveyor movements.

This machine costs around 300USD excluding the component PLC. As this method of construction of machine was hit and trail this amount of money is used in many experimental process. On considering from the manufacturer view the machine can be manufactured for around 100USD including the controller where the PLC is replaced by microcontrollers.

Now, there are no intermediate labors/farmers are required to perform this action and also safety priorities are increased with this machine. Usually in India, only on the road sides or outside the buildings the green coconut is available for consumption. But on installing "Automatic money collecting system "with this machine helps to overcome the above problem and this machine can be placed inside the corporate canteens also like automatic coffee machines etc. Due to economic reasons the fixing of coconut is not automated but it can be updated within the expense of 100USD.

\section{References}

[1] M.A. Oommen, Kerala economy since independence (Oxford \& IBH Pub. Co., New Delhi, 1979).

[2] Raw Cashew and Machinery. URL: http://www.cashewmachineryindia.in (2016)

[3] R.K. Singal, Mridual Singal, Rishi Singal, Basics of Mechanical Engineering (I.K. International Publishing House Pvt. Limited, New Delhi, 2007)

[4] R.K. Rajput, A Textbook of Manufacturing Technology (Firewall Media, New Delhi, 2007)

[5] J.E. Shigley, C.R. Mischke, Standard Handbook of Machine Design (McGraw-Hill, New York, 1986)

[6] T. Bartelt, Industrial Automated Systems: Instrumentation and Motion Control. 1st Edition (Cram101 Textbook Reviews, 2011)

[7] L.A. Bryan, E.A. Bryan, Programmable controllers. Theory and implementation (Industrial Text Company, 1997)

[8] A.J. Tripp, Basic electricity (Van Valkenburgh, Nooger \& Neville, Inc., 1992)

[9] A.K. Gupta, S.K. Arora, Industrial Automation and Robotics (Laxmi Publications, New Delhi, 2007)

[10] D.W. Pessen, Industrial Automation: Circuit Design and Components (John Wiley \& Sons, New York, 1989)

[11] SIMATIC S7-200. URL:

http://w3.siemens.com/mcms/programmable-logic-controller/en/simatic-s7-controlle r/ s7-200/pages/default.aspx (2016) 